\title{
Transvaginal sonography versus saline infusion sonohysterography, which has better diagnosing accuracy in detecting cause of abnormal uterine bleeding in perimenopausal women?
}

\author{
Saika*, Tania Singh \\ Department of Obstetrics and Gynecology, GMC, Srinagar, Jammu and Kashmir, India \\ Received: 01 October 2019 \\ Revised: 05 November 2019 \\ Accepted: 12 November 2019 \\ *Correspondence: \\ Dr. Saika, \\ E-mail: saika2002@gmail.com \\ Copyright: () the author(s), publisher and licensee Medip Academy. This is an open-access article distributed under \\ the terms of the Creative Commons Attribution Non-Commercial License, which permits unrestricted non-commercial \\ use, distribution, and reproduction in any medium, provided the original work is properly cited.
}

\begin{abstract}
Background: Saline infusion sonohysterography (SIS) is a simple, safe, reliable, effective and well-tolerated method without complications that complements transvaginal sonography (TVS) in the pre-operative examination of uterine pathology. SIS has been found to be superior to TVS in most studies that have compared their effectiveness in detecting intracavitary lesions and has also been found to decrease the number of diagnostic hysteroscopies to as much as $50 \%$. Patients in whom no intracavitary abnormality is detected by SIS require no further evaluation and are best treated with medical therapy.

Methods: The observational study was conducted in the postgraduate department of gynaecology and obstetrics, Lalla Ded Hospital, Government Medical College Srinagar. All consecutive patients with perimenopausal abnormal uterine bleeding attending gynaecology OPD were enrolled in the study after taking informed written consent.

Results: SIS has better accuracy than TVS in diagnosing the cause of AUB in perimenopausal women. TVS had sensitivity, specificity and PLR of 60 and 93.8, 9.8, respectively for fibroids while polyps had 27.3, 98.8 and 17.5, respectively, AUP had 81.8, 79.2, 3.9 respectively. SIS had sensitivity, specificity, PLR and NLR values of 80.0, 96.9, 40.7 and 0.21 , respectively for diagnosing fibroids, while 63.6, 98.4, 26 and 0.37 respectively for polyp, and 90.9, 94.3, 16.1 respectively for AUP.

Conclusions: Accuracy of SIS as a test for detecting pathology in AUB in perimenopausal patients is moderately good and suitable for developing countries.
\end{abstract}

Keywords: Abnormal uterine bleeding, Abnormal uterine pathology, Perimenopausal bleeding, Saline infusion sonohysterography, Transvaginal sonography

\section{INTRODUCTION}

AUB is responsible for as many as $1 / 3$ of all outpatient gynaecological visits and this proportion rises to $69 \%$ in perimenopausal age group. ${ }^{1,2}$ The approach recommended in cases of perimenopausal bleeding is to begin by performing the simplest, easy and non-invasive method acceptable to the patients, is the transvaginal sonography. ${ }^{3}$ Transvaginal sonography plays an important role as initial modality. ${ }^{4}$ By the widespread use of transvaginal sonography, the number of invasive procedures such as hysteroscopy can thus be reduced. Intrauterine space occupying lesions including submucosal myomas, endometrial polyp and cancer can be accurately diagnosed by transvaginal sonography and their location and size also delineated. ${ }^{5}$ The prevalance of these benign intracavitary abnormality is approx $35 \% .^{6}$ However, major limitation of transvaginal sonography is 
higher false-negative rate in diagnosing focal uterine pathology. This results in part from the physicial inability of transvaginal sonography to clearly assess the endometrium when there is concurrent uterine pathology such as leiomyomas or polyps. These women warrant either saline infusion sonography for further evaluation regardless of endometrial thickness. ${ }^{7,8}$ However, the specificity of endometrial thickness measurement is low, therefore not suitable for identifying cases of intracavitary endometrial abnormalities. ${ }^{9} \quad 1 / 6$ of endometrial lesions are missed or are not diagnosed when transvaginal sonography is used alone in the perimenopausal patient. Increasingly, saline infusion sonography is recommended to further evaluate the endometrium in perimenopausal women with abnormal bleeding when the endometrial echo is normal on transvaginalsonography. ${ }^{7,10}$

Intrauterine infusion of saline solution during saline infusion sonography is a new diagnostic technique in which uterine cavity is distended thereby enabling visualization of endometrial surface. ${ }^{11}$ Anything that can significantly improve the accuracy of diagnosing the cause of bleeding can reduce the frequency of hysterectomy. SIS in the evaluation of PMB is more economical and less painful. It helps in decision making, segregates high risk patients for further work-up and definitive surgery. In addition to being acceptable and accurate, it can greatly reduce the demand for hysteroscopy. ${ }^{12}$

For the identification and assessment of uterine lesions, SIS is a simple, safe, reliable, effective and well-tolerated method without complications that complements TVS in the pre-operative examination of uterine pathology. SIS has been found to be superior to TVS in most studies that have compared their effectiveness in detecting intracavitary lesions and has also been found to decrease the number of diagnostic hysteroscopies to as much as $50 \% .{ }^{13}$ It could also half the number of interventions in pre and postmenopausal women with normal histological findings. ${ }^{14}$ Patients in whom no intracavitary abnormality is detected by SIS require no further evaluation and are best treated with medical therapy. SIS reduce the number of unnecessary surgical procedures and, thus, lower costs and reduce morbidity in the evaluation of abnormal uterine bleeding in women. ${ }^{15}$

\section{METHODS}

The observational study was conducted in the Postgraduate department of gynaecology and obstetrics, Lalla Ded Hospital, Government Medical College Srinagar, over a period of one and a half year over a from April 2015 to October 2016. All consecutive patients with perimenopausal abnormal uterine bleeding attending gynaecology O.P.D were enrolled in the study after taking informed written consent and clearance from institutional ethical committee.

\section{Inclusion criteria}

- Perimenopausal women in the age group of 40-50 years presenting with abnormal bleeding.

\section{Exclusion criteria}

- Uterus size $>12$ weeks

- Hormone therapy within last 6 months

- Previous abnormal endometrial biopsy

- Positive pregnancy test

- Cervical pathology on per speculum examination.

- Abnormal cervical PAP smear

- Any history and evidence suggestive of acute pelvic infections.

\section{Methodology}

In this prospective study, after thorough history taking, clinical examination and exclusion of cervical pathologies by vaginal speculum and cervical Pap smear examination, informed written consent was taken from every eligible patient. Transvaginal sonography was done followed by saline infusion sonography in the same sitting.

\section{Statistical analysis}

Statistical Software SPSS (Version 16.0) was used to carry out the statistical analysis of data. Descriptive Statistics of data including the mean and standard deviation for numerical variables and the percentages of different categories for categorical variables was obtained. Frequency distribution tables, bar and pie charts were used for data presentation. Sensitivity, Specificity, PLR and NLR values were obtained to assess the accuracy of TVS and SIS in diagnosis of patients with perimenopausal abnormal uterine bleeding.

\section{RESULTS}

Abnormal uterine bleeding in perimenopausal age group is a common but ill defined entity which needs proper evaluation. The present study was conducted in the department of obstetrics and gynaecology Lalla Ded Hospital, Govt. Medical College, Srinagar. A total of 75 patients with perimenopausal bleeding were included in the study. The demographics of age showed that most of our study population belonged to age group $44-47$ years $(41.3 \%)$ with a mean age of 45.2 years. Normal findings were found in $32(42.7 \%)$ of patients on transvaginal sonography (TVS) while hyperplasia was seen in 29 $(38.7 \%)$, fibroid in $10(13.3 \%)$ (Figure 1) and polyp in 4 $(5.3 \%)$ of patients (Table 1$)$.

The SIS findings were normal in 34 (45.3\%) of patients, hyperplasia seen in $23(30.7 \%)$, fibroid in $10(13.3 \%)$ (Figure 2 ) and polyp in $8(10.7 \%)$ (Figure 3 ) of patients (Table 2). 
Table 1: TVS findings of patients.

\begin{tabular}{|ll|l|}
\hline TVS findings & No. & Percentage \\
\hline Normal & 32 & 42.7 \\
\hline Hyperplasia & 29 & 38.7 \\
\hline Fibroid & 10 & 13.3 \\
\hline Polyp & 4 & 5.3 \\
\hline Total & $\mathbf{7 5}$ & $\mathbf{1 0 0}$ \\
\hline
\end{tabular}

Table 2: SIS findings of patients.

\begin{tabular}{|lll|}
\hline SIS findings & No. & Percentage \\
\hline Normal & 34 & 45.3 \\
\hline Hyperplasia & 23 & 30.7 \\
\hline Fibroid & 10 & 13.3 \\
\hline Polyp & 8 & 10.7 \\
\hline Total & $\mathbf{7 5}$ & $\mathbf{1 0 0}$ \\
\hline
\end{tabular}

TVS had sensitivity, specificity and PLR of 60 and 93.8, 9.8, respectively for fibroids while polyps had 27.3, 98.8 and 17.5, respectively, AUP had 81.8, 79.2, 3.9 respectively (Figure 4).

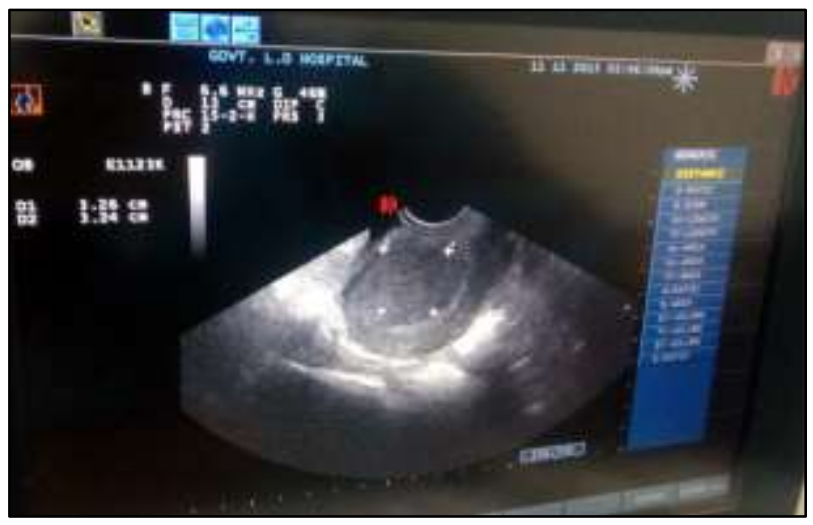

Figure 1: Fibroid on TVS.

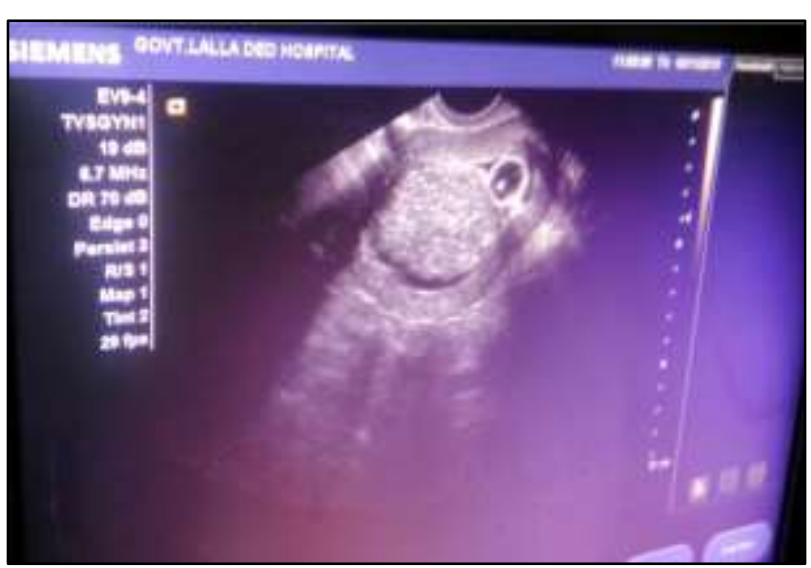

Figure 2: Fibroid on SIS.

SIS had sensitivity, specificity, PLR and NLR values of 80.0, 96.9, 40.7 and 0.21 , respectively for diagnosing fibroids, while $63.6,98.4,26$ and 0.37 respectively for polyp and 90.9, 94.3, 16.1 respectively for AUP (Figure $5)$.

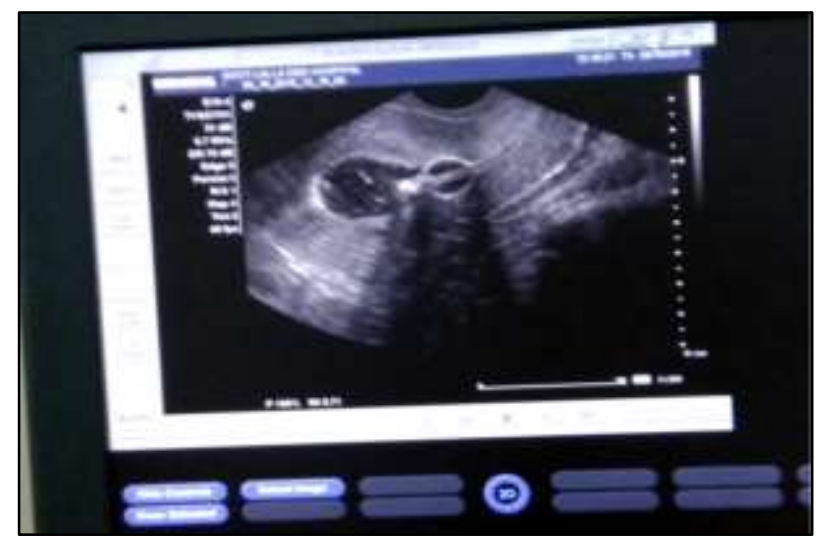

Figure 3: Polyp on SIS.

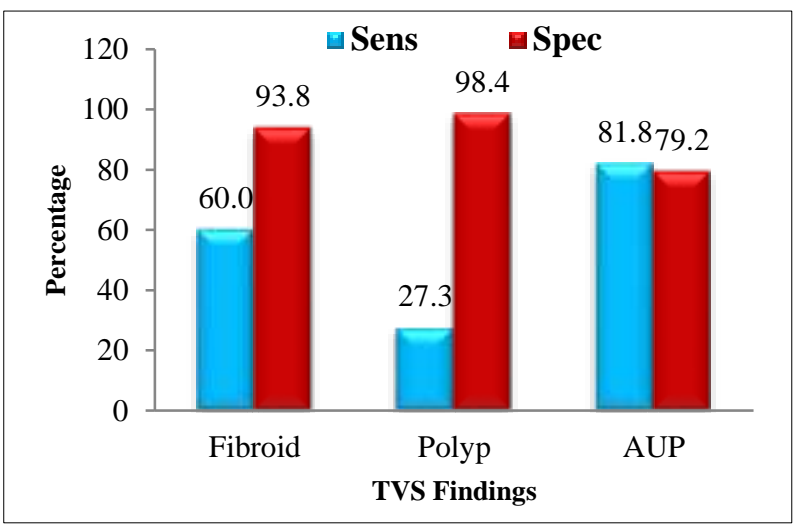

Figure 4: Diagnostic accuracy of TVS.

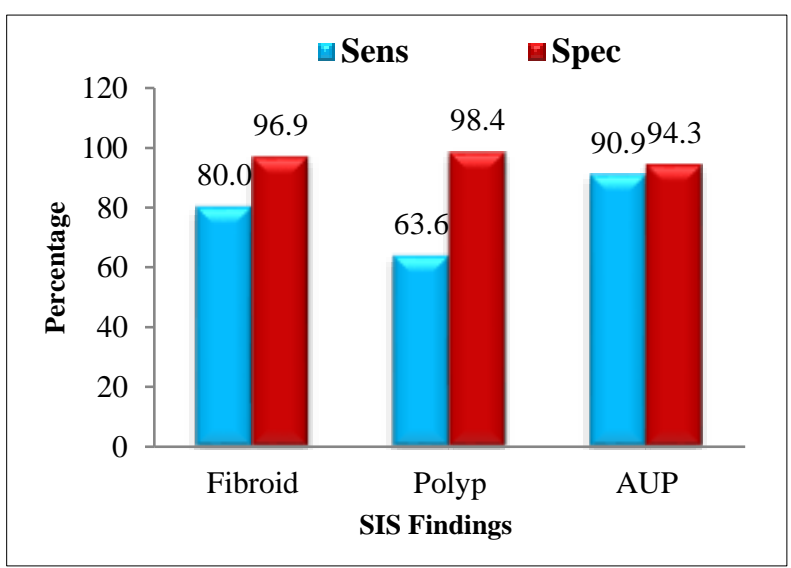

Figure 5: Diagnostic accuracy of SIS.

\section{DISCUSSION}

Abnormal uterine bleeding in perimenopausal age group is a common but ill defined entity which needs proper evaluation. The present study was conducted in the department of obstetrics and gynaecology Lalla Ded Hospital, Govt. Medical College, Srinagar. A total of 75 patients with perimenopausal bleeding were included in 
the study. The demographics of age showed that most of our study population belonged to age group 44-47 yrs $(41.3 \%)$ with a mean age of $45.2 \mathrm{yrs}$ which was comparable to the study done by Dijkhuizen FPHLJ et al and Dasgupta $\mathrm{S}$ et al. where mean age was 45 years and 46.2 years, respectively. ${ }^{10,14}$

Present study showed TVS and SIS had no abnormal finding in $32(42.7 \%)$ and $34(45.3 \%)$ patients, respectively. Hyperplasia was found in 29 (38.7\%) and $23(30.7 \%)$ patients by TVS and SIS, respectively. Both TVS and SIS detected $10(13.3 \%)$ patients with fibroids. $4(5.3 \%)$ and $8(10.7 \%)$ patients with polyps when observed through TVS and SIS, respectively. This was comparable with study done by Subhankar D et al in which TVS was found to be normal $35.7 \%$ women while $7.1 \%$ women with polyps and $13.9 \%$ had fibroids. ${ }^{10}$ While, SIS had following findings $39.7 \%$ normal, $9.3 \%$ polyp and $16.6 \%$ had fibroids.

In the present study, fibroids were diagnosed by TVS with a sensitivity and specificity of 60 and 93.8, polyps with 27.3 sensitivity and 98.4 specificity. AUP was diagnosed by TVS with 81.8 and 79.2 sensitivity and specificity respectively.

On TVS positive likelihood ratio (PLR) and negative likelihood values of patients with fibroid was 9.8 and 0.43 , respectively; 17.5 and 0.74 , respectively in women with polyps while Results were comparable to study by Subhankar D et al by using TVS, fibroid had sensitivity, specificity, PLR and NLR of 65.7, 97.4, 25.3, 0.35 respectively while polyp and AUP had sensitivity of 25, 86.4 specificity of 95.2, 69.3 PLR of 5.2, 2.8 and NLR of $0.78,0.2$ respectively. ${ }^{10}$

In the study, when diagnosed through SIS, women with fibroids had sensitivity, specificity, PLR and NLR values of $80.0,96.9,40.7$ and 0.21 , respectively. Women, when diagnosed with polyp by SIS had sensitivity, specificity, PLR and NLR values of 63.6, 98.4, 26.0 and 0.37 respectively, while SIS had sensitivity, specificity, PLR and NLR values of 90.9, 94.3, 16.1 and 0.10 respectively for diagnosing AUP. In a study by Subhankar D et al SIS had sensitivity and specificity, PLR, NLR of 85.7, 98.7, $65.4,0.14$ respectively for fibroid; $58.3,90.6$ and 24.3 , 7.5 respectively for polyp and 97.6, 88, 0.42, 0.1 respectively for AUP which is consistent with present study. ${ }^{10}$

The problem is the uterine bleeding has a wide range of diagnostic possibilities and confusion is generated. From the present study, it is clear that accuracy of SIS as a test for detecting pathology in AUB in perimenopausal patients is good and suitable for developing countries. The concern of today's gynaecologist while evaluating abnormal uterine bleeding is not to miss a significant cancerous lesion. SIS in the evaluation of PMB is more economical and less painful. It helps in decision making, segregates high risk patients for further work-up and definitive surgery.

In addition to being acceptable and accurate, it can greatly reduce the demand for the number of unnecessary surgical procedures and, thus, lower costs and reduce morbidity in the evaluation of abnormal uterine bleeding in women.

\section{CONCLUSION}

It can be concluded from this study that SIS has better accuracy than TVS and no further evaluation is needed if no intracavitary abnormality is detected and these patients with PMB can be treated with medical therapy. SIS is a simple, safe, reliable, effective and well tolerated method in detecting cause of AUB in perimenopausal women.

\section{Funding: No funding sources}

Conflict of interest: None declared

Ethical approval: The study was approved by the Institutional Ethics Committee

\section{REFERENCES}

1. Awwad JT. Abnormal uterine bleeding in the perimenopause. Int J Fertil. 1993;38:261-9.

2. Wren BG. Dysfunctional uterine bleeding. Aust Family Physic. 1998;54:61-72.

3. Breitkopf D. Detection of benign endometrial masses by endometrial stripe measurement in premenopausal women. Obstet Gynecol. 2004;104:120-5.

4. Hoffman BL. Abnormal uterine bleeding, benign general gynecology. Williams Gynecology. 1st ed. United States: McGraw-Hill Companies, 2008.

5. Dijkhuizen FPHLJ. The accuracy of transvaginal ultrasonography in the diagnosis of endometrial abnormalities. Obstet Gynecol. 1996;87:345-9.

6. Bradley L. Hysteroscopy: office evaluation and management of the uterine cavity. 1st ed. Philadelphia: Mosby- Elsevier. 2009:110-112.

7. Parsons AK. Sonohysterography for endometrial abnormalities: preliminary results. J Clin Ultrasound. 1993;21:87-95.

8. Gupta JK. Ultrasonographic endometrial thickness for diagnosing endometrial pathology in women with postmenopausal bleeding: a meta-analysis. Acta Obstet Gynecol Scand. 2002;81:799- 816.

9. Gull B. Can ultrasound replace dilatation and curettage? A longitudinal evaluation of postmenopausal bleeding and transvaginal sonographic measurement of the endometrium as predictors of endometrial cancer. Am J Obstet Gynecol. 2003;188:401-8.

10. Subhankar D. Abnormal uterine bleeding in permenopausal age: diagnostic options and accuracy. J Obst Gynaecol India. 2011;4:189-94. 
11. Bradley L. Hysteroscopy: office evaluation and management of the uterine cavity. 1st ed. Philadelphia: Mosby- Elsevier. 2009:110-112.

12. Yildizhan B. Transvaginal ultrasonography and saline infusion sonohysterography for the detection of intra-uterine lesions in pre- and post-menopausal women with abnormal uterine bleeding. Journal Int Med Research. 2008;36:1205-13.

13. Vercellini P. The role of transvaginal ultrasonography and outpatient diagnostic hysteroscopy in the evaluation of patients with menorrhagia. Human Repro. 1997;12(8):1768-71.

14. Dijkhuizen F. Comparison of transvaginal ultrasonography and saline infusion sonography for the detection of intracavitary abnormalities in premenopausal women. Ultrsound Obstet Gynecol. 2000;15:372-6.
15. Dueholm M. Transvaginal sonography combined with saline contrast sonohysterography in evaluating the uterine cavity in premenopausal patients with abnormal uterine bleeding. Ultrasound Obstet Gynecol. 2001;18:54-61.

Cite this article as: Saika, Singh T. Transvaginal sonography versus saline infusion sonohysterography, which has better diagnosing accuracy in detecting cause of abnormal uterine bleeding in perimenopausal women? Int J Reprod Contracept Obstet Gynecol 2019;8:4829-33. 